\title{
Papaya (Carica papaya) consumption is unsafe in pregnancy: fact or fable? Scientific evaluation of a common belief in some parts of Asia using a rat model
}

\author{
Adebowale Adebiyi, P. Ganesan Adaikan* and R. N. V. Prasad \\ Department of Obstetrics and Gynaecology, National University of Singapore, 10 Kent Ridge Crescent, Singapore 119260
}

(Received 22 August 2001 - Revised 4 February 2002 - Accepted 4 March 2002)

\begin{abstract}
Using controlled in vivo and in vitro pharmacological methods, we evaluated the safety of papaya (Carica papaya) consumption in pregnancy with reference to its common avoidance during pregnancy in some parts of Asia. Ripe papaya (Carica papaya L. (Caricaecae) blend $(500 \mathrm{ml} / 1$ water) was freely given to four groups of Sprague-Dawley rats at different stages of gestation (days 1-5, 6-11, 12-17 and 1-20). The control group received water. The effect of ripe papaya juice and crude papaya latex on pregnant and non-pregnant rats' uteri was also evaluated using standard isolated-organ-bath methods. The daily volumes $(\mathrm{ml})$ of ripe papaya blend consumed by the treated group were significantly $(P<0 \cdot 05)$ more than water consumed by the control (control 40.3 (SD 11.6) v. treated 64 (SD 19.0)). There was no significant difference in the number of implantation sites and viable fetuses in the rats given ripe papaya relative to the control. No sign of fetal or maternal toxicity was observed in all the groups. In the in vitro study, ripe papaya juice $(0.1-0.8 \mathrm{ml})$ did not show any significant contractile effect on uterine smooth muscles isolated from pregnant and non-pregnant rats; conversely, crude papaya latex $(0 \cdot 1-3 \cdot 2 \mathrm{mg} / \mathrm{ml})$ induced spasmodic contraction of the uterine muscles similar to oxytocin $(1-64 \mathrm{mU} / \mathrm{ml})$ and prostaglandin $\mathrm{F}_{2 \alpha}(0.028-1.81 \mu \mathrm{M})$. The response of the isolated rat uterine smooth muscles to $0.2 \mathrm{mg}$ crude papaya latex $/ \mathrm{ml}$ was comparable to $0.23 \mu \mathrm{M}$ prostaglandin $\mathrm{F}_{2 \alpha}$ and $32 \mathrm{mU}$ oxytocin $/ \mathrm{ml}$. In the $18-19 \mathrm{~d}$ pregnant rat uterus, the contractile effect of crude papaya latex was characterized by tetanic spasms. The results of the present study suggest that normal consumption of ripe papaya during pregnancy may not pose any significant danger. However, the unripe or semi-ripe papaya (which contains high concentration of the latex that produces marked uterine contractions) could be unsafe in pregnancy. Though evaluation of potentially toxic agents often relies on animal experimental results to predict risk in man, further studies will be necessary to ascertain the ultimate risk of unripe papaya-semi-ripe papaya consumption during pregnancy in man.
\end{abstract}

Papaya: 'Hot' and 'cold' foods: Uterine contractions: Crude papaya latex: Pregnancy: Indigenous beliefs

In India, the fruit that is widely classified as harmful in pregnancy is papaya (Carica papaya). Women are strictly forbidden from eating ripe and unripe papaya for fear of its teratogenic and abortifacient effects. A study among 1200 women from all districts of Tamil Nadu in India showed that $82 \%$ of women avoided papaya during pregnancy (Ferro-Luzzi, 1980). In Indonesia, Malaysia and Myanmar, different parts of the papaya have been used indigenously as abortifacients (Keharo \& Bouquet, 1950; Quisumbing, 1951; Tang, 1979). Furthermore, some foods are classified as 'hot' or 'cold' according to indigenous beliefs in parts of Asia. 'Hot' foods are often believed to be harmful during pregnancy and those classified as 'cold' are believed to be harmless (Nag, 1994). Papaya, a staple fruit, is among the foods perceived as 'hot'.

The 'hot' and 'cold' food beliefs are still widely held. Moreover, malnutrition in pregnancy is among the primary aetiologies of low birth weight and of maternal and infant mortality, especially in developing countries. Papaya is a source of vitamin $\mathrm{A}$ and $\beta$-carotene, which are needed for feto-maternal well-being. Hence, scientific evidencebased studies are necessary to separate myths from facts with regard to 'hot' and 'cold' foods.

In the present study, we investigated the effect of oral 
administration of ripe papaya blend during different phases of pregnancy in Sprague-Dawley rats. In addition, we evaluated the effect of ripe papaya juice and crude latex on the isolated pregnant and non-pregnant rat uterus.

\section{Materials and methods}

\section{Animals}

Fertile male $(n$ 10) and virgin female ( $n$ 45) SpragueDawley rats $(200-250 \mathrm{~g})$ were housed in the animal holding unit of the Faculty of Medicine, National University of Singapore; they were allowed to acclimatize for at least 1 week. The animals were maintained under standard laboratory animal conditions. Food and water were made available ad libitum. The experiments in the present study were conducted in accordance with institutional guidelines.

\section{Preparation of ripe papaya}

Ripe and edible fruits of Carica papaya L. (Caricaceae) were purchased from fruit stores in Singapore; the skins were peeled off and the seeds removed. The edible flesh was washed in distilled water, cut into pieces and blended into a fine and pure blend. A further blend was prepared by addition of equal volumes of distilled water $(500 \mathrm{ml} / \mathrm{l})$ and the mixtures were well shaken. Fresh papaya blend was given to the rats every day of the experiment.

\section{Effect of ripe papaya on different phases of pregnancy in rats}

Female rats were individually paired with males until mating was confirmed by the presence of sperm in vaginal smears examined under a light microscope or the presence of dislodged vaginal plug. The day sperm or vaginal plugs were found was designated as day 0 of pregnancy. The pregnant female rats were subsequently assigned to five experimental groups of five rats per group.

The ripe papaya blend $(500 \mathrm{ml} / \mathrm{l})$ was given daily through a water bottle to the treatment groups during different phases of their pregnancy: pre fetal-implantation (days 1-5), post fetal-implantation (days 6-11 and 1217) and throughout gestation (days 1-20). No attempt was made to force-feed the animals. The control group received water. The daily volumes of ripe papaya blend and water consumed by each rat in treatment and control groups were documented. Weight changes of the rats were also noted.

On day 16 of gestation, Caesarean sections were performed on the female rats that received ripe papaya blend before fetal implantation (days 1-5). During the Caesarean sections, the numbers of implantations were recorded for each rat. Furthermore, on day 20 of gestation, Caesarean sections were performed on the female rats that received ripe papaya blend post fetal-implantation (days 6-11 and 12-17) and throughout gestation (days 1-20). During the Caesarean sections, the following variables were recorded for each rat: number of fetal deaths and viable fetuses, as well as the fetal weights. Fetuses were also observed for external malformations. Each treated group was compared with the control using Student's paired $t$ test. The results were expressed as mean values and standard deviations. Differences were considered significant at $P<0 \cdot 05$.

\section{Preparation of ripe papaya juice and crude latex for isolated-organ-bath study}

In the preliminary study, incisions were made on unripe papaya fruit and the white milky latex exudates were collected in a clean bottle. The latex was diluted by the addition of distilled water $(100 \mathrm{ml} / \mathrm{l})$ and subsequently tested on non-gravid isolated rat uterus. Further study on the latex was done using crude papaya latex purchased from Sigma-Aldrich Co. (St Louis, MO, USA). Product information reveals that the dried latex was neither cleaned nor purified; it was packed in a crude and powdered form as received from Africa. The latex was weighed and dissolved in normal saline. The supernatant fraction of ripe papaya blend centrifuged for $30 \mathrm{~min}$ (3000 rpm) was also used for the organ-bath study.

\section{Isolated uterine preparation}

Uterine smooth muscles were obtained from $18-19 \mathrm{~d}$ pregnant and oestrogen-primed, non-pregnant rats. The rats were killed by $\mathrm{CO}_{2}$ asphyxiation and the two uterine horns removed and dissected into strips. The uterine strips (approximately $1.5 \mathrm{~cm}$ each) were mounted vertically under resting tension of $2 \mathrm{~g}$ in a $10 \mathrm{ml}$ organ bath containing freshly prepared new De Jalon solution maintained at $37^{\circ} \mathrm{C}$ and gassed with $\mathrm{O}_{2}-\mathrm{CO}_{2}(95: 5, \mathrm{v} / \mathrm{v})$. The composition of new De Jalon solution used in the present study was (mM): $\mathrm{NaCl} 154 \cdot 00, \mathrm{KCl} 5 \cdot 63, \mathrm{CaCl}_{2} 0 \cdot 27, \mathrm{NaHCO}_{3}$ 5.95 , glucose 2.78 . The pregnant and non-pregnant uterine muscles were allowed to equilibrate in the physiological solution for at least 1 and $2 \mathrm{~h}$ respectively. Responses of the isolated uterine strips to $1-64 \mathrm{mU}$ oxytocin $/ \mathrm{ml}$ (Sandoz, East Hanover, NJ, USA), 0.028-1.81 $\mu \mathrm{M}$ prostaglandin $\mathrm{F}_{2 \alpha}$ (Upjohn, Kalamazoo, MI, USA), 0.1-3.2 mg crude papaya latex/ml (Sigma-Aldrich Co.) and 0.1$0.8 \mathrm{ml}$ ripe papaya juice were isometrically recorded on Mac Lab multi channel chart recorder (AD Instruments, Castle Hill, New South Wales, Australia).

Each concentration of the drugs or test substances was allowed to act for $10 \mathrm{~min}$. The resting period between successive concentrations of the test substances after wash was at least $20 \mathrm{~min}$. The force of spontaneous contractions of the uterine smooth muscles was compared with the individual effect of the test substances using Student's paired $t$ test $(P<0 \cdot 05)$.

\section{Results \\ In vivo study}

All the treated rats showed normal behaviour throughout the present study. The daily volumes $(\mathrm{ml})$ of papaya blend consumed by the rats in the treatment groups were significantly more than the water taken by their control counterpart (control 40.3 (SD 11.6) v. treated 64 (SD 19.0)). 
Table 1. Post-implantation effect of ripe papaya in rats*

(Mean values and standard deviations for five rats per group)

\begin{tabular}{|c|c|c|c|c|c|c|}
\hline \multirow[b]{2}{*}{ Group } & \multirow[b]{2}{*}{ Test substance } & \multirow[b]{2}{*}{ Treatment time (d) } & \multicolumn{2}{|c|}{$\begin{array}{c}\text { Viable } \\
\text { fetuses }(n)\end{array}$} & \multicolumn{2}{|c|}{$\begin{array}{l}\text { Weight of } \\
\text { viable fetuses } \\
\text { (g) }\end{array}$} \\
\hline & & & Mean & SD & Mean & SD \\
\hline 1 & Water (control) & $1-20$ & $14 \cdot 4$ & $2 \cdot 3$ & $4 \cdot 1$ & 0.9 \\
\hline 2 & Papaya blend & $6-11$ & $14 \cdot 2$ & 0.4 & $4 \cdot 1$ & 0.4 \\
\hline 3 & Papaya blend & $12-17$ & $13 \cdot 8$ & 1.9 & $3 \cdot 8$ & 0.7 \\
\hline 4 & Papaya blend & $1-20$ & $15 \cdot 6$ & 1.5 & $4 \cdot 1$ & 0.7 \\
\hline
\end{tabular}

${ }^{*}$ For details of procedures, see p. 200.

The difference in the mean number of fetuses in all the treated groups relative to the control did not show any significant findings. Fetal weights in the treated groups compared with the control also did not reveal any significant differences (Table 1). No fetal death occurred in any of the groups. External examination of all the fetuses revealed no abnormalities. In the rats given ripe papaya before fetal implantation, no significant differences were noted in number of implantation sites relative to the control (control $14.4(\operatorname{SD~2.3)} v$. treated $13.8(\operatorname{SD~} 0.8))$.

\section{In vitro study}

In the isolated-organ-bath study, uterine smooth muscles from non-pregnant rats (primed with $50 \mu \mathrm{g}$ oestradiol benzoate/kg per $\mathrm{d}$ before the experiments) did not show any rhythmic spontaneous contractions within $2 \mathrm{~h}$ of sus-
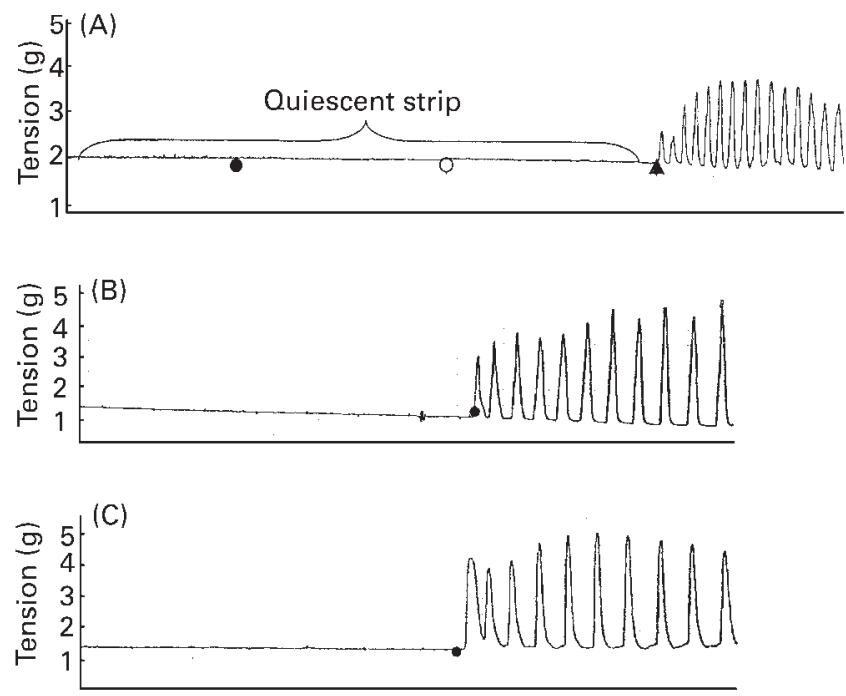

Fig. 1. Sample tracing showing the effects of: (A) ripe papaya juice $(\bullet, 0.4 \mathrm{ml})$, wash $(O)$ and crude papaya latex $(\Lambda, 0.2 \mathrm{mg} / \mathrm{ml})$; $(\mathrm{B})$ prostaglandin $\mathrm{F}_{2 \alpha}(\bullet, 0.23 \mu \mathrm{M})$; (C) oxytocin $(\bullet, 32 \mathrm{mU} / \mathrm{ml})$ on oestrogen-primed, non-pregnant rat uterus in vitro. Uterine smooth muscles from non-pregnant rats (primed with $50 \mu \mathrm{g}$ oestradiol benzoate/kg $1 \mathrm{~d}$ before the experiments) did not show any rhythmic spontaneous contractions within $2 \mathrm{~h}$ of suspension in new De Jalon solution. Ripe papaya juice did not show any effect on the quiescent uterine strips. Conversely, crude papaya latex exerted pronounced contractile effect on the uterine muscles comparable with the effect of standard oxytocics, prostaglandin $\mathrm{F}_{2 \alpha}$ and oxytocin. For details of procedures, see p. 200. pension in new De Jalon solution. Ripe papaya juice did not show any contractile effect on the quiescent uterine strips. Conversely, crude papaya latex exerted pronounced contractile effect on the uterine muscles (Fig. 1(A)). There was a concentration-related increase in basal tone of the uterine contractions. Fig. 2 shows the effect of fresh latex from unripe papaya fruit on non-pregnant rat uterus in vitro.

In 18-19d pregnant rat uterus, spontaneous rhythmic contractions were observed within $1 \mathrm{~h}$ of suspension in new De Jalon solution. Ripe papaya juice did not show any significant contractile effect on the isolated uterus. In contrast, crude papaya latex significantly stimulated the uterine smooth muscles characterized by strong tetanic spasms (Fig. 3 and Table 2). Under the same experimental conditions, the oxytocic effect of $0.2 \mathrm{mg}$ crude papaya latex/ml was comparable with $0.23 \mu \mathrm{M}$ prostaglandin $\mathrm{F}_{2 \alpha}$ and $32 \mathrm{mU}$ oxytocin/ml (Figs 1 and 3 ).

\section{Discussion}

Explaining the common avoidance of papaya consumption during pregnancy in Tamil Nadu communities in India, Ferro-Luzzi (1980) referred to the Tamil term for papaya, 'papali', which comprises two parts, 'pappa' meaning little child, 'ali' meaning to destroy. This indicates the strong belief in the destructive ability of papaya during pregnancy in India.

In rats, fetal implantation occurs between days 5 and 6 of pregnancy; and it has been reported that leucocytic infiltration in the endometrium and stroma is increased during

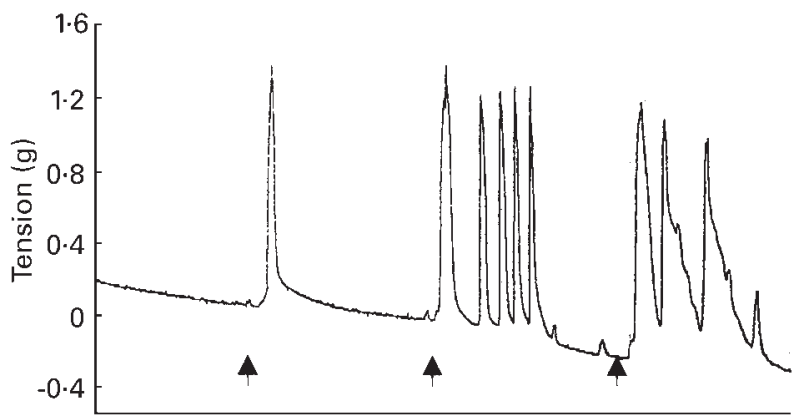

Fig. 2. Sample tracing showing the effect of crude papaya latex $(100 \mathrm{ml} / \mathrm{l}$; from fresh unripe fruit) on non-gravid, oestrogen-primed rat uterus in vitro. For details of procedures, see p. 200. $\uparrow$, addition of latex $(0.2,0.4,0.8 \mathrm{ml})$. 
(A)
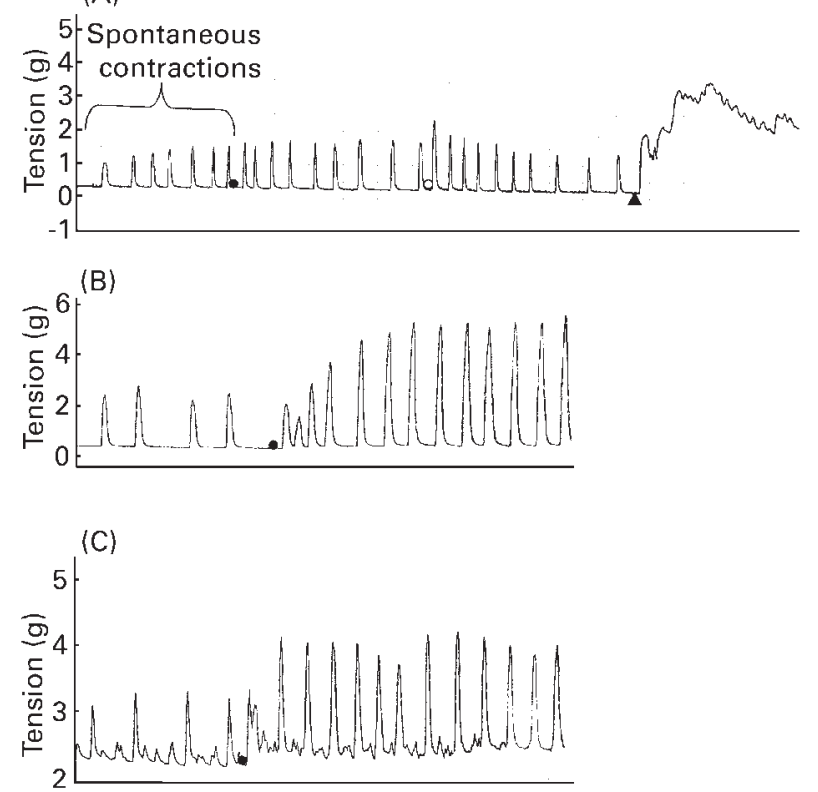

Fig. 3. Sample tracing showing the effect of: $(A)$ ripe papaya juice $(\bullet, 0.4 \mathrm{ml})$, wash $(\mathrm{O})$ and crude papaya latex $(\boldsymbol{\Lambda}, 0.2 \mathrm{mg} / \mathrm{l})$; (B) prostaglandin $\mathrm{F}_{2 \alpha}(\bullet, 0.23 \mu \mathrm{M})$; (C) oxytocin $(\bullet, 32 \mathrm{mU} / \mathrm{ml})$ on uterine strip isolated from pregnant rats. In $18-19 \mathrm{~d}$ pregnant rat uterus, spontaneous rhythmic contractions were observed with $1 \mathrm{~h}$ of suspension in new De Jalon solution. Ripe papaya juice did not show any significant contractile effect on the isolated uterus. In contrast, crude papaya latex significantly stimulated the uterine smooth muscles characterized by strong tetanic spasms. For details of procedures, see p. 200.

the early days of pregnancy with the result that the endometrium becomes highly receptive on day 5 (Lobel et al. 1967). Anti-implantation agents may elicit their effect either hormonally or by local effect on the blastocyst leading to preimplantation loss. Abortifacients cause marked uterine stimulation and subsequent expulsion of the contents.

In the present study, the volumes of papaya blend consumed by the rats in the treatment groups were significantly more than the water taken by their control counterpart. This could be due to the sugar content of the fruit. Ripe papaya did not show any toxic, anti-implantation or abortifacient effects in the rats. Even the rats that were treated from first to the last day of pregnancy did not show any adverse effect from ripe papaya. Furthermore, the effect of the ripe papaya juice on isolated gravid and non-gravid rat uterus shows that it may not provoke any significant uterine stimulation that could be harmful to the fetus or cause abortion.

There are plants in the animal or human diet that could have accidental anti-fertility effects. For example, oral administration of Artemisia tridentata, Juniperus communis and Pinus contorta (plants utilized as food by both domestic and wild ruminant animals) have been reported to cause abortion in domestic sheep and cattle (Johnson et al. 1976; Gardner et al. 1998). Gossypol (present in cotton seeds) was discovered as a potential male contraceptive agent after it was observed that cooking with cottonseed oil in parts of China led to reduced male fertility (Waller et al. 1986; Williamson et al. 1996). Scientific study of plants in diet suspected of having anti-fertility effects are thus necessary to appraise their safety.

Oxytocin is widely used for labour induction (Chard, 1994), while analogues of prostaglandins have been reported to be successful in the induction of abortion by various routes of administration in rodents (Lau et al. 1975; Elger et al. 1981) and human subjects (Karim et al. 1971). Induction of labour-abortion by these drugs is mainly due to their ability to cause strong contractions of the pregnant uterus. The present investigation has shown that papaya latex has oxytocic properties similar to the in vitro effects of oxytocin and prostaglandin $\mathrm{F}_{2 \alpha}$ in pregnant and non-pregnant rat uterus. This suggests that crude papaya latex could be a potential abortifacient.

The main constituents of papaya latex are papain and chymopapain (Calam et al. 1985). Devi \& Singh (1978) reported marked oedema and haemorrhagic placentas in fetuses of the rats given oral and intra-peritoneal doses of papain. We have also observed the potent uterine-stimulating effect of papain and chymopapain on isolated guineapig uterus (A Adebiyi, PG Adaikan and RNV Prasad unpublished results). Papaya latex has been shown to contribute to protecting the plant against predators (El Moussaoui et al. 2001). The levels of latex in fully ripe papaya fruit has not been shown. However, observations suggest that the level of the latex in papaya fruit reduces as it ripens. A fully ripe papaya fruit may thus contain very little or a negligible quantity of the latex which may

Table 2. Maximum force of uterine contractions induced by the test substances on non-pregnant and pregnant rat uterus in vitroł‡ (Mean values and standard deviations for seven uteri per group)

\begin{tabular}{|c|c|c|c|c|}
\hline & \multicolumn{2}{|c|}{ Non-pregnant } & \multicolumn{2}{|c|}{ Pregnant } \\
\hline & Mean & SD & Mean & SD \\
\hline Control (spontaneous contractions) & \multicolumn{2}{|c|}{0 (quiescent) } & $1 \cdot 24$ & $1 \cdot 30$ \\
\hline Ripe papaya juice $(0.1-0.8 \mathrm{ml})$ & 0 & & 1.96 & 1.96 \\
\hline Crude papaya latex $(0.2-3.2 \mathrm{mg} / \mathrm{ml})$ & $2 \cdot 90^{*}$ & 1.00 & $3 \cdot 02^{*}$ & $1 \cdot 17$ \\
\hline Oxytocin $(1-64 \mathrm{MU} / \mathrm{ml})$ & $3.01^{*}$ & 0.97 & $3.56^{\star}$ & 0.91 \\
\hline $\mathrm{PGF}_{2 \alpha}(0.028-1.81 \mu \mathrm{M})$ & $2 \cdot 53^{*}$ & $1 \cdot 11$ & $4 \cdot 69^{*}$ & 1.97 \\
\hline
\end{tabular}

$P G$, prostaglandin.

Mean values were significantly different from control values: ${ }^{*} P<0.05$.

†For details of procedures, see p. 200.

$¥$ The force of uterine contractions was taken as the tension $(\mathrm{g})$ above the baseline value. 
not provoke uterine contractions. Hence, the unripe or semi-ripe papaya (which contains high concentration of the latex that produces marked uterine contractions) may have an adverse effect during pregnancy and should be avoided. It is possible that those patients who are prone to spontaneous abortion-preterm labour due to increased myometrial excitability may be more vulnerable to the lesser amount of papaya latex.

While evaluation of potentially toxic agents often depends on animal bioassay data to predict risk in man, other experimental approaches will be necessary to ascertain the ultimate risk of unripe papaya-semi-ripe papaya consumption during pregnancy in man.

\section{References}

Calam DH, Davidson J \& Harris R (1985) High performance liquid chromatographic investigation on some enzymes of papaya latex. Journal of Chromatography 326, 103-111.

Chard T (1994) Oxytocin in human parturition. In The Uterus, p. 268 [T Chard and JG Grudzinskas, editors]. Cambridge: Cambridge University Press.

Devi S \& Singh S (1978) Changes in placenta of rat fetuses induced by maternal administration of papain. Indian Journal of Experimental Biology 16, 1256-1260.

Elger W, Eskola J \& Csapo AI (1981) Mechanism of action of an orally active $\mathrm{PGE}_{1}$ analogue in pregnant guinea pigs. Prostaglandins 21, 259-266.

El Moussaoui A, Nijs M, Paul C, Wintjens R, Vincentelli J, Azarkan M \& Looze Y (2001) Revisiting the enzymes stored in the laticifers of Carica papaya in the context of their possible participation in the plant defence mechanism. Cell and Molecular Life Sciences 58, 556-570.

Ferro-Luzzi EG (1980) Food avoidance of pregnant women in Tamil Nadu. In Food, Ecology and Culture: Readings in the Anthropology of Dietary Practices, pp. 101-108 [John RK Robson, editor]. New York, NY: Gordon and Breach Science Publishers.
Gardner DR, Panter KE, James LF \& Stegelmeier BL (1998) Abortifacient effects of lodgepole pine (Pinus contorta) and common juniper (Juniperus communis) on cattle. Veterinary and Human Toxicology 40, 260-263.

Johnson AE, James LF \& Spillett J (1976) The abortifacient and toxic effects of big sagebrush (Artemisia tridentata) and juniper (Juniperus osteosperma) on domestic sheep. Journal of Range Management 29, 278-280.

Karim SSM, Hillier K, Somers K \& Trussell RR (1971) The effects of prostaglandins $\mathrm{E}_{2}$ and $\mathrm{F}_{2 \alpha}$ administered by different routes on the uterine activity and the cardiovascular system in pregnant and non-pregnant women. Journal of Obstetrics and Gynaecology of the British Commonwealth 78, 172-179.

Keharo J \& Bouquet A (1950) Plantes Medicinales et Toxiques de la Cote d'Ivoire Haute Volta (Medicinal and Poisonous Plants in the Ivory Coast Upper Volta). Paris: Vigot Freres.

Lau IF, Saksena SK \& Chang MC (1975) Prostaglandin $F_{2}$-alpha for induction of midterm abortion: a comparative study. Fertility and Sterility 26, 74-79.

Lobel BL, Levi E, Kisch ES \& Shelesnyak MC (1967) Studies on the mechanism of nidation - experimental investigation on the origin of eosinophillic granulocytes in the uterus of rats. Acta Endocrinologica 55, 45-47.

Nag M (1994) Beliefs and practices about food during pregnancy. Economic and Political Weekly, India. September 10, pp. 2427-2438.

Quisumbing EA (1951) Medicinal Plants of the Philippines, Department of Agricultural and Natural Resources Technical Bulletin 16. Philippines: Manila Bureau of Printing.

Tang CS (1979) Macrocyclic piperidine and piperidine alkaloid in Carica papaya. Food Chemistry and Nutrition 1, 55-68.

Waller DP, Niu X \& Kim I (1986) Toxicology and mechanism of action of gossypol. In Male Contraception: Advances and Future Prospects, pp. 183-200 [GI Zatuchni, A Goldsmith, JM Spieler and JJ Sciarra, editors]. Philadelphia, PA: Harper \& Row Publishers.

Williamson EM, Okpako DT \& Evans FJ (1996) Pharmacological Methods in Phytotherapy Research, 1st ed. Vol. 1. Selection, Preparation and Pharmacological Evaluation of Plant Material. Chichester: John Wiley \& Sons Ltd. 